\title{
Vegetarianism vs. meatarianism and emotional upset
}

\author{
LAWRENCE WEINSTEIN \\ Brandon University, Brandon, Manitoba R7A 6A9, Canada \\ and \\ ANTON F. de MAN \\ Bishop's University, Lennoxville, Quebec J1M 1Z7, Canada
}

\begin{abstract}
Subjects who ingested vegetables for breakfast for 8 days were compared with subjects who ate meat breakfasts for 8 days on scales of emotional upset. Two response measures indicated significantly more negative emotionality for the meat eaters than for the vegetable eaters. The present results are discussed in terms of the limited previously existing date and possible blood chemistry mediation.
\end{abstract}

The popular controversy of whether or not vegetarianism is superior to "meatarianism" very much rests at the level of opinion: Limited empirical data are available. The question of the effects of vegetable vs. meat ingestion when calories are equated on human emotional and personality variables has received even less vocalization and laboratory study.

The present study was undertaken to obtain needed information about the effects of vegetable vs. meat ingestion at breakfast, when the calories in the two types of food are equated. People's feelings of frustration, or, more generally, irascibility, were measured by test scores from the Rosenzweig Picture Frustration Test (Rosenzweig, 1967) and a self-rating scale.

\section{METHOD}

Subjects

The subjects, 20 males, were enrolled in courses at Simon Fraser University. They were assigned randomly to each of two equal groups, vegetable eaters (Group V) and meat eaters (Group M).

\section{Apparatus and Procedure}

For 7 consecutive preexperimental days, daily calorie intakes and body weights were recorded.

During these preexperimental days, subjects ate their usual breakfasts, but in the laboratory. On Day 8 , the 1 st day after the 7 th preexperimental day, the 1 st of the 8 consecutive experimental days began (the experiment proper). During Experimental Days 8-15 the V subjects ate $336 \mathrm{~g}$ of raw carrots (120 calories) and $280 \mathrm{~g}$ of raw cauliflower ( 80 calories) for breakfast, for a total of 200 calories; the $M$ subjects ingested $112 \mathrm{~g}$ (weighed raw) of dry fried (fried without any oil or fat) round steak (200 calories). Condiments, including salt, were not used. Each group was required to imbibe 2 cups of black coffee with the vegetables or meat. All subjects were allowed no more

Requests for reprints can be sent to Dr. L. Weinstein, Psychology Department, Brandon University, Brandon, Manitoba R7A 6A9, Canada. than $30 \mathrm{~min}$ to eat the food and drink. Subjects were told that they were being asked to eat the vegetables or meat to see the effects of various foods on body health, such as stamina. Furthermore, $\mathrm{V}$ and $\mathrm{M}$ subjects were told that each food had already been found to increase staying power (stamina) throughout the day. Daily "nonmorning" calorie intakes were not restricted and were measured; body weights were recorded each day. Subjects ate their breakfasts alone in the laboratory and then went about their daily matters. They weighed themselves at home each night before retiring and recorded in a personal diary all caloried substances ingested in that day.

On each of the 8 experimental days and the 7 preexperimental days starting at 12:00 noon, subjects completed a selfrating scale. Rating himself on a scale from 0 to 60 , the individual indicated how upset, aggressive, or generally frustrated he felt up to that time in his day. A rating of 60 indicated most frustrated and 0 , least frustrated. Just previous to his self-rating, the subject was administered the Rosenzweig Picture Frustration Test. According to Rosenzweig (1967), individuals who score relatively high on the test are more emotionally distressed, irascible, or generally (at least while taking the test) more sensitive to the emotional consequences of frustrating situations than are low scorers. Before taking the Rosenzweig test and the rating scale, all subjects were told that these tests were being administered to collect preliminary data for another experiment they would participate in later in the year, an experiment dealing with mood swings at different times of the day. Each subject was randomly assigned to a time of Rosenzweig and ratingscale testing, so that neither Group V nor Group $M$ was tested consistently at the same daily hour.

\section{RESULTS}

Body weight and calorie intake per day for the 7 preexperimental days each showed no significant difference between Groups V and M. By an analysis of variance, $\mathrm{V}$ ate as many daily calories as $\mathrm{M}$ for the 7 days prior to the introduction of the special breakfast $[\mathrm{F}(1,18)=1.01, \mathrm{p}>.05]$ and weighed as much as $\mathrm{M}$ over the same time period $[\mathrm{F}(1,18)=1.32, \mathrm{p}>.05]$. Each of the two analyses of variance performed for the Rosenzweig and rating-scale results for the 7 preexperi- 


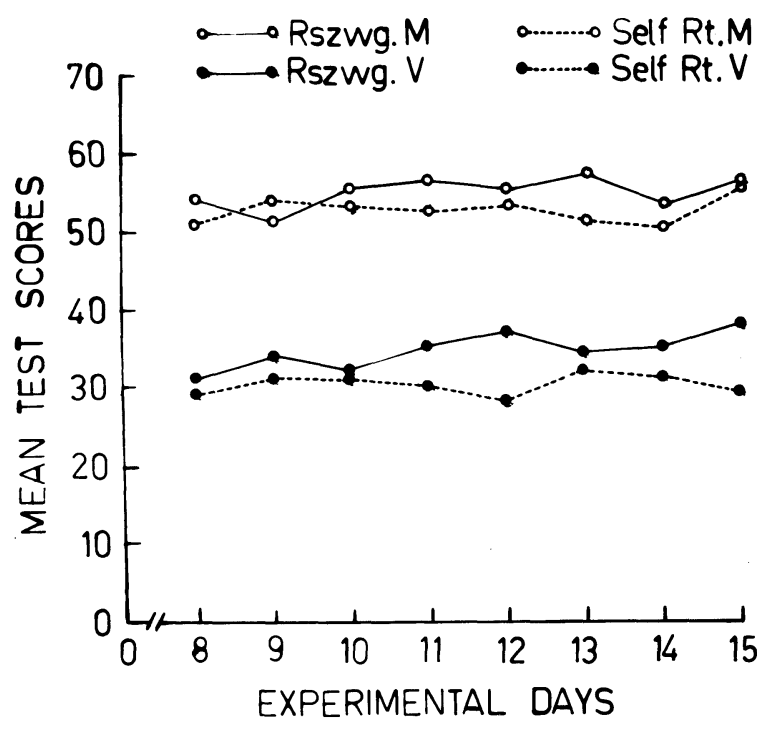

Figure 1. Mean Rosenzweig test scores and mean rating scale scores, each as a function of the experimental days for meat and vegetarian groups.

mental days for $\mathrm{V}$ vs. $\mathrm{M}$ revealed no significance [for Rosenzweig, $F(1,18)=1.91, p>.05$; for the rating results, $F(1,18)=1.03, p>.05]$. Each of the two analyses of variance performed for calorie and weight data for the eight experimental sessions for Groups $\mathrm{V}$ and $M$ also revealed no significance [for calorie consumption, $F(1,18)=2.31, p>.05$; for weight, $F(1,18)=$ $2.04, \mathrm{p}>.05]$.

Considering the Rosenzweig axis, Figure 1 suggests that for Days 8-15 the $M$ subjects scored higher as to frustration than the $\mathrm{V}$ subjects.

The mean Rosenzweig test scores for Days 8-15 were statistically different for the two groups by an analysis of variance $[\mathrm{F}(1,18)=7.75, \mathrm{p}<.05]$, with $\mathrm{V}$ subjects having a mean of 34.5 and $M$ subjects a mean of 54.6.

Regarding the rating-scale axis, Figure 1 shows that for Days 8-15 the M subjects scored higher than those in Group V.

The mean rating-scale test scores from Days 8-15 differed statistically among $\mathbf{M}$ and $\mathbf{V}$ by an analysis of variance $[F(1,18)=7.83, p<.05]$, with the $V$ subjects having a mean of 30.1 and the $M$ subjects a mean of 52.1 .

\section{DISCUSSION}

The data from Preexperimental Days 1-7 revealed that intended V subjects were the same as intended $M$ subjects in terms of how frustrated or irascible the two groups felt. The results from Experimental Days 8-15, however, showed clearly that subjects who ingested vegetables at breakfast felt less emotionally upset than those who ingested meat. Since neither body weight per day nor daily calorie intake was statistically different between $V$ and $M$ subjects over the experimental days, the observed emotional differences were very likely not due to a relatively uncomplicated hunger drive variable; that is to say, both groups should have been equally hungry at the time of Rosenzweig and rating-scale testings.

The observed differences in human emotionality agree with the very limited data available relative to meat vs. vegetable ingestion and emotionality (e.g., Kramarcy \& Thurmond, Note 1 ). The data have generally shown that infrahumans are more aggressive when exposed for relatively brief (i.e., 2-week) periods of time to high-protein diets compared with lower protein eating regimens. In the present investigation, a high-protein diet is represented by the eating habits of the $M$ subjects, with the $V$ subjects' eating consisting of proportionally less protein (than M) and more carbohydrates.

The present investigation suffers from a possible subjectexpectancy effect. That is, perhaps the $\mathrm{V}$ subjects thought they were expected to behave less upset than the $M$ subjects. A further study is needed that controls for the subjects' awareness of the food they are ingesting and/or control of the subjects' expectancy as to the effects of the two substances (vegetables and meat) used in the experiment.

It is also possible that the explanation of the present emotional disparity may be found in the blood chemistry of the two groups, V and $\mathrm{M}$; the blood chemistry question is open for empirical examination.

In any case, it would seem that eating vegetables for breakfast produces, in general, less emotional upset than ingesting meat for breakfast, whatever the reason may be.

\section{REFERENCE NOTE}

1. Kramarcy, N. R., \& Thurmond, J. B. Effects of dietary leucine, phenylalanine, and tryptophan on territorial aggression in the mouse. Paper presented at the annual meeting of the Psychonomic Society, St. Louis, Missouri, November 1976.

\section{REFERENCE}

Rosenzweic, S. Revised criteria for the group conformity rating of the Rosenzweig Picture Frustration Test, adult form. Journal of Projective Techniques and Personality Assessment, 1967, 31, 58-61.

(Received for publication November 30, 1981.) 